\title{
Expression of a novel DREB 5-A subgroup transcription factor gene from Ricinus communis (RcDREB1) enhanced growth, drought tolerance and pollen viability in tobacco
}

Francisco Lima Aragão ( $\nabla$ francisco.aragao@embrapa.br)

Embrapa: Empresa Brasileira de Pesquisa Agropecuaria https://orcid.org/0000-0003-0570-7673

Tomas Felipe Costa do Rego

Embrapa: Empresa Brasileira de Pesquisa Agropecuaria

Mirella Pupo Santos

Universidade Federal do Rio de Janeiro

Glaucia Barbosa Cabral

Embrapa: Empresa Brasileira de Pesquisa Agropecuaria

Thaís de Moura Cipriano

UPIS

Natália Lima de Sousa

Embrapa: Empresa Brasileira de Pesquisa Agropecuaria

Otacílio Antônio de Souza Neto

Embrapa: Empresa Brasileira de Pesquisa Agropecuaria

\section{Research Article}

Keywords: Dehydration Responsive Element Binding, environmental stress tolerance, genetic engineering, transgenic tobacco, water-deficit stress tolerance

Posted Date: March 2nd, 2021

DOl: https://doi.org/10.21203/rs.3.rs-277040/v1

License: (c) (1) This work is licensed under a Creative Commons Attribution 4.0 International License. Read Full License

Version of Record: A version of this preprint was published at Plant Cell, Tissue and Organ Culture (PCTOC) on April 21st, 2021. See the published version at https://doi.org/10.1007/s11240-021-02082-7. 


\section{Abstract}

Climate change has increased the frequency of long periods of drought, affecting crop cultivation worldwide. Losses due to water stress exceed ten percent of world production of major crops, reaching three-quarters of production areas, with severe economic losses. Therefore, the generation of environmental stress-tolerant genotypes that are more efficient in water use is extremely important. We have previously isolated and characterized a DREB transcription factor coding gene, named RCDREB1, from castor bean (Ricinus communis $L$.), which probably belongs to the CBF/DREB subfamily subgroup A-5. Aiming to develop drought-tolerant lines, we have stably introduced and expressed the RCDREB1 transgene into tobacco. Transgenic lines have revealed an enhanced drought tolerance. Genetically modified lines cultivated under water deficit presented a higher photosynthetic rate, stomatal conductance, leaf water potential and leaf water content when compared to the control. Transgenic lines revealed lower transpiration rates. In addition, biometric analyses showed that transgenic lines cultivated under water stress presented higher biomass, higher fresh and dry weight and higher plant height than the non-transgenic lines. After re-watering, transgenic lines recovered faster than non-transgenic plants. Moreover, pollen grains from transgenic plants revealed a remarkable increase in viability after exposure to heat $\left(38^{\circ} \mathrm{C}\right)$ and desiccation stresses. The results presented here will be the foundation for production of commercial crops that are more tolerant to environmental stresses and long-life pollen grains, increasing pollination and in consequence, productivity.

\section{Introduction}

Water stress affects plant growth and development and is the main abiotic stress to which plants are subjected (Hafez et al. 2020). Climate change has increased the frequency of long periods of drought, affecting crop cultivation worldwide and generating considerable pressure on global agricultural yields (Leng and Hall 2019). Losses due to water stress exceed $10 \%$ of world production of major crops, reaching three quarters of production areas, which corresponds to 454 million hectares, with economic losses of approximately US\$ 166 billion per year (Mishra et al. 2021). A study on the loss of production due to drought was carried out, and the results showed that the risk of losses will reach between $9 \%$ and $19 \%$ for various crops (Leng and Hall 2019). Therefore, it is vital to generate tolerant and efficient genotypes regarding the use of water.

Aiming to develop drought-tolerant cultivars, molecular breeders have isolated and characterized genes that could be used for genetic transformation (for a review see Shinwari et al. 2020). Candidate genes include those that encode for transcription factors (TFs) that act as molecular switches, participating in important signaling pathways (Alexander et al. 2019; Kang et al. 2019; Li et al. 2020). Numerous transcription factors genes have already been tested by genetic engineering, for example, $D R E B 2 A$, AtGolS2 and AtHsfA2 in Arabidopsis thaliana (Takahashi et al. 2020), MdERF38 in apple (An et al. 2020), Pflp in banana (Nansamba et al. 2020) and AtGolS2 in soybean (Takahashi et al. 2020). 
DREB (Dehydration Responsive Element Binding) transcription factors belong to the superfamily of APETALA2/Ethylene Responsive Factor (AP2/ERF), and have been characterized as a key regulator of the expression of plant biotic and abiotic stress-responsive genes, as well as for obtaining genetic modified crops that are tolerant to abiotic stresses (Peleg et al. 2011; Liang et al. 2017; Li et al. 2020, Sharma et al. 2020). The AP2/ERF superfamily is divided into subfamilies AP2 - APETALA2, RAV - related to ABI3/VP, CBF/DREB and ERF - Ethylene Responsive Element Binding Factor (Mizoi et al. 2012; Abiri et al. 2017). $\mathrm{CBF} / \mathrm{DREB}$ proteins contain a highly conserved DNA binding domain that specifically promotes cis-acting DRE/CRT (Dehydration Responsive Element/C-repeat) genes, activated by stresses caused by water deficiency and low temperature (Lata and Prasad 2011; Srivastava and Kumar 2019). The CBF/DREB subfamily is composed of six subgroups based on their similarity to AP2: A (1-6) and AP2: B domains (Khan 2011; Akhtar et al. 2012). Subgroups A-1 and A-2 are better described than others in the same subgroup, and are involved in the activation of ABA-independent genes related to the response to stresses such as cold, drought, salinity (Khan 2011; Maruyama et al. 2009; Huang et al. 2020), water deficit and high temperature (Matsukura et al. 2010; Lata and Prasad 2011; Reis et al. 2014). Subgroups A-3 and A-4 could also induce abiotic stress tolerance ( $\mathrm{Li}$ et al. 2015) and are involved in growth regulation, impairing cell division (Li et al. 2018). Subgroups A-5 and A-6 are still not well characterized, but have also been identified as stress inducible proteins, since they are ABA-responsive (Kizis and Pages 2002; Chen et al. 2007; Chen et al. 2008; Sun et al. 2014).

We have isolated and characterized an AP2/ERF TF gene (named RcDREB1) from castor bean (Ricinus communis $\mathrm{L}$.) coding for a protein that presented $38-78 \%$ identity when compared to other AP2/ERF TF proteins (Cipriano et al. 2013). In R. communis, RCDREB1 transcripts were only observed in pollen grains, peaking during anthesis. Phylogenetic analysis classified it as a member of the CBF/DREB subfamily, rooting with subgroup A-5 (Cipriano et al, 2013). The RCDREB1 promoter was fused to the gus reporter gene and its expression observed in several tissues of transgenic tobacco plants exposed to low and high temperatures, drought, salinity and exogenous ABA (Cipriano et al. 2013). However, no detectable gus gene expression was observed. We observed gus expression in pollen grains during anthesis. It was also confirmed in castor bean. As castor bean is used to growing under hot and dry environments, anthesis is the moment that pollens are exposed to severe conditions, suggesting that RCDREB1 would play a role in the protection of pollen cells from adverse stressing circumstances.

Based on our previous results, we hypothesized that the constitutive expression of RCDREB1 in a transgenic plant would promote tolerance to dehydration. In this work, we evaluated this hypothesis by expressing the gene in transgenic tobacco plants and assessing their tolerance to water stress, as well as pollen viability under adverse conditions.

\section{Material And Methods}

\section{Vector construction and tobacco transformation}


The coding sequence of the RCDREB1 gene was synthesized at Epoch Inc. (Missouri City, TX, USA), according to GenBank accession number JQ361741.1 and cloned into pBI426 (Datla et al. 1991), replacing the gus-neo gene fusion between $\mathrm{Ncol}$ and Sacl. The expression cassette, with the RcDREB1 gene driven by a double $35 \mathrm{~S}$ Cauliflower mosaic virus (CaMV) promoter plus a leader sequence from Alfalfa mosaic virus (AMV), was then transferred to pCambia3300 with EcoRI and HindIII, generating the vector PC-RcDREB1 (Figure 1a), which was transfected into A. tumefaciens EHA105 and used to transform tobacco, according to Horsch et al. (1985).

\section{Screening of transgenic tobacco plants}

Regenerated plants were first screened using the immunochromatographic strip test TraitChekTM (Romer Labs) based on the manufacturer's instructions for the detection of the PAT protein, encoded by the bar gene. DNA from leaves was isolated according to Edwards et al. (1991). PCR reactions were carried out in

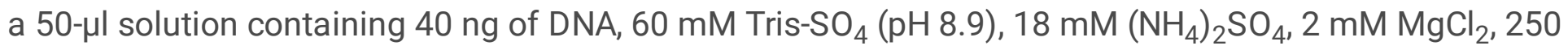
$\mathrm{nM}$ of each dNTP, $200 \mathrm{nM}$ of each primer, and $5 \mathrm{U}$ of Taq polymerase (Invitrogen). The mixture was incubated at $95^{\circ} \mathrm{C}(5 \mathrm{~min})$ and subjected to 35 cycles of amplification $\left(95^{\circ} \mathrm{C}\right.$ for $1 \mathrm{~min}, 55^{\circ} \mathrm{C}$ for $1 \mathrm{~min}$, and $72^{\circ} \mathrm{C}$ for $1 \mathrm{~min}$ ), with a final elongation cycle of $5 \mathrm{~min}$ at $72^{\circ} \mathrm{C}$. The $567 \mathrm{bp}$ of the RCDREB 1 coding sequence was amplified using the primer pair RcDREB54R (ACATCCGAATCTTCCGGGTC) / RcDREB2F (GGAAATGGAAGGCGAAACGG). Reaction mixtures were loaded directly onto a $1 \%$ agarose gel stained with ethidium bromide and visualized under UV light.

\section{Progeny analysis}

Five transgenic lines were selected $(T 6, T 11, T 16, T 17$ and $T 20)$ and allowed to set seeds. Seeds of the first generation $\left(T_{1}\right)$ of self-pollinated plants were germinated and analyzed for the presence of the RCDREB1 gene by PCR, as previously described. Pearson's Chi squared test $\left(\mathrm{X}^{2}\right)$ was used to determine whether the observed segregation ratios were consistent with a Mendelian ratio (3:1) at 95\% level of confidence.

\section{Quantitative real-time RT-PCR analysis (RT-qPCR)}

RNA isolation and the RT-qPCR assay were performed as described by Andrade et al. (2015). Three biological replications for each line were used for the cDNA synthesis. The primers for the RCDREB1 transgene, ATAAGGATGAGAAAGTGGG (RTRCDREBF) and GCAACAGGAGTCGAATAAG (RTRCDREBR), were designed using the PrimerQuest Tool (IDT Integrated DNA Technologies, Inc). The elongation factor $1 a(E F-1 a)$ transcripts were used as an internal reference to normalize gene expression (Schmidt and Delaney 2010). Triplicate quantitative assays were performed on each cDNA sample. The expression levels were calculated from the threshold cycle according to the $2^{-\triangle \Delta C T}$ method (Livak and Schmittgen 2001).

\section{Drought tolerance trial and physiological analyses}


Transgenic and non-transgenic plants were cultivated in 2-L pots containing red latoso/ soil and were grown for 70 days in a greenhouse, at $27 \pm 5{ }^{\circ} \mathrm{C}$, and irrigated daily. For each analysis, seven blocks with 16 plants were used for each line in a randomized block design. Plants were subjected to water deficit for 9 days by withdrawing irrigation water. Several physiological parameters were measured every three days as described by Vieira et al. (2017), including photosynthetic rate, stomatal conductance, transpiration, leaf water potential and leaf water content. The fifth and sixth leaves, and a portable infrared gas analyzer, model LC-Pro SD, ADC, were used. The leaf water potential $\left(\Psi_{\mathrm{W}}\right)$ was measured daily, between 7 and 9 am, on a fully expanded and photosynthetically active leaf, using a Scholander pressure chamber (SAPSII model 3115, Soil Moisture). The relative water content (RWC) and fresh weight (FW) were carried out as described (Vieira et al. 2017). Experiments were repeated twice.

Biometric analyses were carried out after the period of nine-day water-deficit stress, when root length and plant height were measured. The percentage of growth inhibition generated by the stress was determined by comparing plant height not exposed to water stress. For the recovery analyses, the irrigation was restored, and the recovery was recorded by photographic, and water potential measured after $0 \mathrm{~h}, 4 \mathrm{~h}$ and $8 \mathrm{~h}$. Water potential was measured on the second leaf from the top to the bottom on the plants.

In order to study the effect of ABA on seed germination, seeds from transgenic and non-transgenic lines were germinated on MS medium supplemented with ABA at 0, 5, 10 and $20 \mathrm{mg} / \mathrm{L}$. Germination was quantified daily for two weeks.

\section{Proline quantification in leaves}

Proline was extracted from lyophilized tobacco leaves $(10 \mathrm{mg}$ ) according to Carillo and Gibon (2011). Proline content was determined spectrophotometrically at $570 \mathrm{~nm}$ (Spectra Max 190, Molecular Devices).

\section{Pollen viability assay}

Pollen grains were collected from 8 am to 9 am, deposited on a moistened paper in a Petri dish and incubated at $38^{\circ} \mathrm{C}$ for $1 \mathrm{~h}$, under dry conditions. In order to measure viability, pollen grains were treated with fluorescein diacetate $(5 \mu \mathrm{g} / \mathrm{ml})$ for $5 \mathrm{~min}$ and observed under a Zeiss Axiophot fluorescence microscope (under blue-light excitation) and photographed. Pollen was quantified using a Neubauer chamber. Viable pollen grains present a yellow-green fluorescence.

\section{Statistical analysis}

The statistical analyses using the GraphPad Prism Software 6 were carried out by means of a completely randomized design, with six repetitions. Analysis of variance (ANOVA) was implemented to determine the significant differences $(p<0.05)$ among the evaluated lines, followed by Dunnett's test $(p<0.05)$.

\section{Results}


Regenerated plants were screened for the presence of the RcDREB1 gene by PCR and PAT protein, encoded by the bargene, using the immunochromatographic strip test (Fig. 1b, 1c). Based on this analysis, five lines were chosen, named T6, T11, T16 and T17, for further evaluations. The chi-squared test revealed that the segregation rate of both bar and RCDREB1 transgenes in the $\mathrm{T}_{1}$ generation (selfpollinated), closely fitted the Mendelian ratio of $3: 1$ (line $T 6, X^{2}=1.11, P=0.29$; line $11, X^{2}=0, P=1.00$; line $T 16, X^{2}=1.22, P=0.27$; line $T 17, X^{2}=2.28, P=0.16$ and line $T 20, X^{2}=0.10, P=0.74 ; 1 d f$ ), expected for one locus.

Quantitative real-time RT-PCR analysis was carried out with the five selected lines as an attempt to determine the cause-effect relationship between the RCDREB1 transgene expression and the observed phenotype. The results showed that RCDREB1 was transcribed in leaves of all transgenic lines, from 12.1 to 15.5 times above the control basal signal, presenting a very similar expression level pattern (Fig. 1d).

To investigate the ability of RCDREB 1 to enhance drought tolerance, seven-day-old seedlings were transferred to pots containing latosol, and 70 day-old-plants were subjected to water deficit for 9 days by irrigation water withdrawal. Several physiological parameters were measured, including photosynthetic rate, stomatal conductance, transpiration, leaf water potential and leaf water content. In general, transgenic plants presented evident drought tolerance (Figs. 2 and 3). All transgenic lines presented a higher photosynthetic rate from the sixth day after irrigation withdrawal (Fig. 2), higher stomatal conductance, and lower transpiration rates, when compared to the control (WT) (Fig. 2). Transgenic lines presented higher leaf water potential, six and nine days after irrigation withdrawal, when compared to the control (Fig. 2). In addition, the genetically modified lines showed significantly higher leaf water content than the non-transgenic lines (WT). Nevertheless, no differences were observed in the relative water content in the soil where both transgenic and non-transgenic plants were cultivated (Fig. 2). In general, transgenic lines presented higher instantaneous leaf water use efficiency than the control line (WT), three and six days after irrigation removal (Fig. 3). Figure 3 shows the transgenic lines chosen, namely T6, T11 and T16, and the non-transgenic (WT) plants' behavior under water-deficit stress, nine days after irrigation withdrawal; and the comparison of plants that were exposed and non-exposed to hydric stress. It was observed that the transgenic lines grew faster when compared to the non-transgenic plants, under nonstressing conditions (Figs. $3 \mathrm{~b}$ and c). However, transgenic and non-transgenic lines that were not exposed to stresses presented statistically similar development during this period (Fig. 3c).

Biometric analyses were performed with 70-day-old plants after a period of nine days under water-deficit stress (Fig. 4). It was observed that the transgenic lines presented higher biomass, characterized by a higher fresh shoot (50-70\%), and dry (35-50\%) weight, lower root:shoot ratio, and a higher plant height (52-60\%), when compared to the control WT, non-transgenic plants (Fig. 4).

After the nine-day period of water-deficit stress, plants were re-watered and evaluated for a period of five hours. Measurement of the leaf water potential revealed that transgenic lines recovered faster than nontransgenic lines (Fig. 5). 
Since the RCDREB1 gene's expression in castor bean, from which it was isolated, was only observed in pollen grains, pollen from transgenic tobacco plants was exposed to heat stress at $38^{\circ} \mathrm{C}$, for a period of one hour, followed by an additional period of one hour under dry conditions. At that point, the reduction in pollen viability was evaluated. The results showed that the pollen viability decreased by $63 \%$ in the nontransgenic line (WT), while viability decreased only $20.5 \%$, (line T17) to $3.5 \%$ (line T20) in transgenic lines (Fig. 6).

In order to study the effect of $A B A$ on seedlings expressing the RCDREB1 gene, seeds from transgenic and non-transgenic lines were germinated at $0,5,10$ and $20 \mathrm{mg} / \mathrm{L} A B A$. The results showed a statistical difference in transgenic seeds' germination (Fig. 6). Transgenic seeds germinated more slowly, when exposed to increasing concentrations of $A B A$, than non-transgenic lines, suggesting sensitivity to the hormone.

Since proline is a relevant indicator for plant stress response, we quantified its content in leaves of plants submitted to water-deficit stress in three periods, at 3, 6 and 9 days. The proline amount increased significantly 3 days after irrigation removal in transgenic lines ( 1.7 to 2.5 -fold). However, after 9 days, the proline content was lower in transgenic lines when compared to non-transgenic plants (Fig. 6).

\section{Discussion}

We previously isolated and characterized a DREB coding gene from castor bean (Cipriano et al. 2013). Its expression was observed mainly in pollen, peaking during anthesis, with the flower opening, initiating the senescence process. At this moment, mature pollen grains are released from anthers and exposed to a challenging external environment to which castor bean is well adapted. Thus, we hypothesized that the over-expression of the castor bean $D R E B$ gene in genetically modified plants would generate lines of stress-tolerant genotypes, with some impact on productivity in a scenario of global climate change.

In order to test the primary hypothesis, transgenic tobacco plants were generated to express the RCDREB1 transgene under control of the $35 \mathrm{~S} \mathrm{CaMV}$ promoter. In fact, it was observed that transgenic lines expressing RCDREB1 were more tolerant to water-deficit stress, with higher rates of photosynthesis and water status. This can be explained by higher stomatal conductance, optimizing the efficiency of water use by establishing a positive balance between reduced respiration and $\mathrm{CO}_{2}$ input (Flexas et al. 2013). The conservation of the photosynthesis rates and the relative water content allowed the energy production and the pressure of cell turgor to be maintained for a longer time in the transgenic lines. This resulted in higher rates of vegetative growth when compared to non-transgenic plants. Similar results were observed in tobacco plants overexpressing the SIDREB3 gene, with transgenic lines presenting stomatal conductance, as well as a higher rate of photosynthesis during water stress (Upadhyay et al. 2017).

ABA status is associated with several signaling pathways that eventually cause reduction in growth during stress provoked by dehydration (Osakabe et al. 2014; Wang et al. 2015; Santos et al. 2020). Its 
action during stress results in stomatal closure, inducing stress tolerance in several species. However, the negative impact of stomatal closure and its association with the increase of water efficiency use should be explored. Studies carried out with Arundo donax have shown a relationship between the stoma signaling pathway for $\mathrm{ABA}$ and $\mathrm{CO}_{2}$ (Haworth et al. 2018). It was observed that during drought, $\mathrm{CO}_{2}$ became the strongest signal for stomatal movements, higher than $A B A$, leading to a better performance under water stress conditions (Haworth, et al., 2018). Water use efficiency and carbon incorporation can be modified by reducing stomatal sensitivity to $A B A$ and increasing its sensitivity to $\mathrm{CO}_{2}$.

Phylogenetic analyses have rooted RcDREB1 as a member of the CBF/DREB subfamily A-5 subgroup, in which several proteins have been characterized as stress-inducible, and belonging to the ABA signaling pathway (Mizoi et al. 2012; Bouaziz et al. 2012; Cipriano et al. 2013; Ren et al. 2019). The higher aerial part/root ratios observed in transgenic lines suggest a greater allocation of photo-assimilates to the aerial parts, when compared to the non-transgenic plants. If RcDREB1 were associated with ABAmediated signaling, it would be unexpected to occur under water stress (Jaleel et al. 2009; Xie et al. 2014). Nevertheless, our results suggest that RcDREB1 possibly acts as a negative regulator of $A B A$ action during water stress, inducing less sensitivity to this hormone. We have to consider that stomatal closure was observed more gradually in the transgenic plants, which presented higher growth rates during water stress. In addition, the suppression of germination induced by osmotic stresses, such as $\mathrm{NaCl}$ and Mannitol, and the fact that transgenic lines were less sensitive to ABA during germination, corroborate this hypothesis. Similar results were observed by Upadhyay et al. (2017), in a study that reported the reduction in ABA sensitivity in transgenic tobacco lines expressing the SIDREB3 gene, resulting in greater tolerance to water stress, when compared to control plants. Wang et al. (2015) showed similar results in rice genotypes that overexpressed $\mathrm{OsC} 3 \mathrm{H} 47$, a gene responsive to water stress. They observed that OsC3H47 overexpressing plants were more tolerant to various types of abiotic stress and showed greater growth when treated by increasing doses of ABA. Yin et al. (2017) showed that overexpression of the OsMYBR1 gene, a MYB-type transcription factor, increased tolerance to water stress and decreased sensitivity to ABA. Negin et al. (2019) demonstrated that $A$. thaliana engineered to express an ABAsignaling inhibitor (abi1-1) was more tolerant of the effects of water stress. They suggested that endogenous basal ABA would inhibit an escape response under stress-free conditions, allowing plants to accumulate biomass.

Proline synthesis from glutamate occurs via two enzymatic steps, catalyzed by two $\Delta^{1}$-pyrroline-5carboxlyate synthetases (P5CS) encoded by the genes P5CS1 and P5CS2. P5CS1 gene expression is increased during stress caused by dehydration, while P5CS2 expression is less influenced by environmental changes (Strizhov et al. 1997; Székely et al. 2008; Kavi Kishor and Sreenivasulu 2014). Increase in proline content is reported during seed and pollen maturation (Chibi et al. 1995; Hare et al. 2003). The accumulation of proline is positively associated with ABA-mediated signal transduction during water stress, and its accumulation is associated with increased stress tolerance (Ábrahám et al. 2003; Rotsch et al. 2017). Transgenic tobacco lines presented an initial increase in proline content that did not significantly increase over time, which may indicate a lower sensitivity of these plants to the 
environment and ABA. In contrast, non-transgenic plants responded to stress by accumulating proline, observed by the greater $\Delta_{9-3}$ (accumulation of proline over time). However, this increase, differently from what is reported in the literature, was not enough to promote stress tolerance in these plants.

Recovery after re-irrigation in the transgenic lines was faster when compared to non-transgenic plants, presenting similar leaf water potential values to the non-stressed plants in a four-hour period. It could be attributed to the better hydraulic condition of these plants, allowing more efficient water absorption. The recovery of the plant after re-irrigation depends on the characteristics of the plant species, and the time and intensity of the stress. The root tissue under water stress undergoes modifications that will induce the inhibition of the movement of water and ions through the apoplastic pathway (Taleisnik et al. 1999). Transport of water via the xylem is impaired by drought, which results in tensions in these conductive vessels that lead to cavitation, and the consequent formation of embolisms in the plant. These hinder or prevent recovery after re-irrigation. From that point, known as permanent wilt, stress can no longer be reversed (Kramer and Boyer 1995; Lens et al. 2013).

Our results showed that the transgenic lines presented greater pollen viability when compared to the nontransgenic lines. It will be interesting to explore the production of genotypes of crops in which cross pollination is fundamental for yield, such as orange, maize, strawberry and cotton. Pollen viability time has been the subject of many discussions and has recently been reviewed by Pacini and Douferus (2019). During anthesis, pollen grains are exposed to the environment and require autonomous physiological changes to adapt to environmental fluctuations, being classified as recalcitrant or orthodox, according to desiccation tolerance. During dispersion, pollen undergoes changes such as water loss, and activates homeostatic mechanisms to maintain turgor pressure, with the accumulation of proline and sugars to protect cell functions and maintain viability (Chibi et al. 1995; Kavi Kishor and Sreenivasulu 2014).

Collectively, the results presented here demonstrated that the expression of RCDREB1 promotes the maintenance of vegetative growth and drought tolerance, as well as inducing pollen viability under environmental stress conditions. It is suggested that this transcription factor possibly participates as a negative regulator in the pathway signaled by $A B A$, since RCDREB1-expressing plants were less responsive to this hormone. Further studies should be carried out to better characterize its function in both transgenic plants and castor bean, from which it was isolated.

\section{Abbreviations}

DREB: Dehydration Responsive Element Binding

RcDREB1: Ricinus communis Dehydration Responsive Element Binding

CBF: $C$-repeat binding factor

TFs: transcription factors 
AP2/ERF: APETALA2/Ethylene Responsive Factor

ERF: Ethylene Responsive Element Binding Factor

DRE/CRT: Dehydration Responsive Element/C-repeat

ABA: Abscisic Acid

Gus: $\beta$-glucuronidase gene

CaMV: Cauliflower mosaic virus

AMV: Alfalfa mosaic virus

PAT: Phosphinothricin Acetyl-Transferase

RWC: Relative water content

FW: Fresh Weight

MS: Murashige and Skoog basal salt mixture growth medium

WT: Wild Type

\section{Declarations}

\section{Funding}

Funding was provided by Empresa Brasileira de Pesquisa Agropecuária, Conselho Nacional de Desenvolvimento Científico e Tecnológico and Coordenação de Aperfeiçoamento de Pessoal de Nível Superior.

\section{Acknowledgments}

This work was funded by Conselho Nacional de Desenvolvimento Científico e Tecnológico (CNPq, grant number 307111/2018-0). TFCR was supported by a fellowship from CAPES (Coordenação de Aperfeiçoamento de Pessoal de Nível Superior).

\section{References}

Abiri R, Shaharuddin NA, Maziah M, Yusof ZNB, Atabaki N, Sahebi M, Valdiani A, Kalhori N, Azizi P, Hanafi MM (2017) Role of ethylene and the APETALA 2/ethylene response factor superfamily in rice under various abiotic and biotic stress conditions. Environ Exp Bot 134:33-44. 
Ábrahám E, Rigó G, Székely G, Nagy R, Koncz C, Szabados L (2003) Light-dependent induction of proline biosynthesis by abscisic acid and salt stress is inhibited by brassinosteroid in Arabidopsis. Plant Mol Biol 51:363-372.

Akhtar M, Jaiswal A, Taj G, Jaiswal JP, Qureshi MI. Singh NK (2012) DREB 1 /CBF transcription factors: their structure, function and role in abiotic stress tolerance in plants. $\mathrm{J}$ Genet 91:385-395.

An JP, Zhang XW, Bi SQ, You CX, Wang XF, Hao YJ (2020) The ERF transcription factor MdERF38 promotes drought stress-induced anthocyanin biosynthesis in apple. Plant $\mathrm{J}$ 101:573-589. doi: 10.1111/tpj.14555.

Bouaziz D, Pirrello J, Ben Amor H, Hammami A, Charfeddine M, Dhieb A, Bouzayen M, Gargouri-Bouzid R (2012) Ectopic expression of dehydration responsive element binding proteins (StDREB2) confers higher tolerance to salt stress in potato. Plant Physiology and Biochemistry 60:98-108 https://doi.org/10.1016/j.plaphy.2012.07.029.

Carillo P, Gibon Y (2011) PrometheusWiki. PROTOCOL: Extraction and determination of proline. PrometheusWiki. In: https://www.researchgate.net/publication/211353600

Chaves MM, Pereira JS, Maroco J, Rodrigues ML, Ricardo CP, Osório ML, Carvalho I, Faria T, Pinheiro C (2002) How plants cope with water stress in the field. Photosynthesis and growth. Ann Bot 89:907-916. doi: $10.1093 / \mathrm{aob} / \mathrm{mcf} 105$

Chibi F, Angosto T, Matilla A (1995) Variations of the Patterns of Abscisic Acid and Proline during Maturation of Nicotiana tabacum Pollen Grains. J Plant Physiol 147:3-4.

Cipriano TM, Moraes AT, Aragão FJL (2013) Characterization of a pollen-specific and desiccationassociated AP2/ERF type transcription factor gene from castor bean (Ricinus communis L.). Int J Plant Biol 4:1-7.

Datla RS, Hammerlindl JK, Pelcher LE, Crosby WL, Selvaraj G (1991) A bifunctional fusion between betaglucuronidase and neomycin phosphotransferase: a broad-spectrum marker enzyme for plants. Gene 101:239-246.

Edwards K, Johnstone C, Thompson C (1991) A simple and rapid method for the preparation of plant genomic DNA for PCR analysis. Nucleic Acids Res 19:1349.

Flexas J, Niinemets U, Gallé A, Barbour MM, Centritto M, Diaz-Espejo A, Douthe C, Galmés J, Ribas-Carbo M, Rodriguez PL, Rosselló F, Soolanayakanahally R, Tomas M, Wright IJ, Farquhar GD, Medrano H (2013) Diffusional conductances to $\mathrm{CO}_{2}$ as a target for increasing photosynthesis and photosynthetic water-use efficiency. Photosynth Res. 117:45-59. 
Hafez EM, Omara AED, Alhumaydhi FA, El-Esawi MA (2020) Minimizing hazard impacts of soil salinity and water stress on wheat plants by soil application of vermicompost and biochar. Physiol Plant 1:16. https://doi.org/10.1111/ppl.13261

Hare PD, Cress WA, van Staden J (2003) A regulatory role for proline metabolism in stimulating Arabidopsis thaliana seed germination. Plant Growth Regul 39:41-50.

Horsch RB, Fry JE, Hoffmann NL, Wallroth M, Eichholtz D, Rogers SG, Fraley RT (1985) A simple and general method for transferring genes into plants. Sci 227:1229-1231.

https://doi.org/10.1007/s11816-020-00598-6.

Huang X, Song X, Chen R, Zhang B, Li C, Liang Y, Qiu L, Fan Y, Zhou Z, Zhou H, Lakshmanan P, Li Y, Wu J (2020) Genome-Wide Analysis of the DREB Subfamily in Saccharum spontaneum Reveals Their Functional Divergence During Cold and Drought Stresses. Front Genet 10:1-16. doi:

10.3389/fgene.2019.01326. PMID: 32117408; PMCID: PMC7013043.

Jaleel C, Manivannan P, Wahid A, Farooq M, Al-Juburi H, Somasundaram R, Panneerselvam R (2009) Drought Stress in Plants: A Review on Morphological Characteristics and Pigments Composition. Int J Agric Biol 11:100-105.

Kavi Kishor PB, Sreenivasulu N (2014) Is proline accumulation per se correlated with stress tolerance or is proline homeostasis a more critical issue? Plant Cell Environ 37:300-311. doi:10.1111/pce.12157.

Khan MS (2011) The role of DREB transcription factors in abiotic stress tolerance of plants. Biotechnol Biotechnol Equip 25:2433-2442.

Kizis D, Pagès M (2002) Maize DRE-binding proteins DBF1 and DBF2 are involved in rab17 regulation through the drought-responsive element in an ABA-dependent pathway. Plant J. 30:679-689.

Kramer PJ, Boyer JS (1995) Water relations of plants and soils. Academic Press, San Diego.

Lata C, Prasad M (2011) Role of DREBs in regulation of abiotic stress responses in plants. J Exp Bot 62:4731-4748.

Leng G, Hall J (2019) Crop yield sensitivity of global major agricultural countries to droughts and the projected changes in the future. Sci Total Environ 654:811-821.

Lens F, Tixier A, Cochard H, Sperry JS, Jansen S, Herbette S (2013) Embolism resistance as a key mechanism to understand adaptive plant strategies. Curr Opin Plant Biol 16:287-292.

Lesk C, Rowhani P, Ramankutty N (2016) Influence of extreme weather disasters on global crop production. Nature 529:84-87. 
Li YP, Ye W, Wang M, Yan XD (2009) Climate change and drought: a risk assessment of cropyield impacts. Climate Res 39:31-46.

Li S, Zhao Q, Zhu D, Yu J (2018) A DREB-like transcription factor from maize (Zea mays), ZmDREB4.1, plays a negative role in plant growth and development. Front. In Plant Sci. 9: 1-15. doi:

$10.3389 /$ fpls.2018.00395

Li Q, Qin Y, Hu X, Ding H, Xiong X (2020) Transcriptome analysis uncovers the gene expression profile of salt-stressed potato (Solanum tuberosum L.). Sci Rep 10: 5411. doi: 10.1038/s41598-020-62057-0

Liang Y, Li X, Zhang D, Gao B, Yang H, Wang Y, Guan K, Wood AJ (2017) ScDREB8, a novel A-5 type of DREB gene in the desert moss Syntrichia caninervis, confers salt tolerance to Arabidopsis. Plant Physiol Biochem 120:242-251.

Livak KJ, Schmittgen TD (2001) Analysis of relative gene expression data using realtime quantitative PCR and the $2^{-\triangle \triangle C T}$ method. Methods. 25:402-408.

Maruyama K, Sakuma Y, Kasuga M, Ito Y, Seki M, Goda H, Shimada Y, Yoshida S, Shinozaki K, Yamaguchi-Shinozaki K (2004) Identification of cold-inducible downstream genes of the Arabidopsis DREB1A/CBF3 transcriptional factor using two microarray systems. Plant J 38:982-993.

Matsukura S, Mizoi J, Yoshida T, Todaka D, Ito Y, Maruyama K, Shinozaki K, Yamaguchi-Shinozaki K (2010) Comprehensive analysis of rice DREB2 type genes that encode transcription factors involved in the expression of abiotic stress-responsive genes. Mol Gen Genomics 283:185-196.

Mishra A, Bruno E, Zilberman D (2021) Compound natural and human disasters: Managing drought and COVID-19 to sustain global agriculture and food sectors. Sci Total Environ 754:142210.

doi:10.1016/j.scitotenv.2020.142210

Mizoi J, Shinozaki K, Yamaguchi-Shinozaki K, (2012) AP2/ERF family transcription factors in plant abiotic stress responses. Biochim Biophys Acta 1819:86-96.

https://doi.org/10.1016/j.bbagrm.2011.08.004.

Nansamba M, Sibiya J, Tumuhumbise R. Karamura D, Kurubira J, Karamura E (2020) Breeding banana (Musa spp.) for drought tolerance: A review. Plant Breending 139:685-696. DOI: 10.1111/pbr.12812

Negin B, Yaaran A, Kelly G, Zait Y, Moshelion M (2019) Mesophyll abscisic acid restrains early growth and flowering but does not directly suppress Photosynthesis. Plant Physiol 180:910-925. DOI:

10.1104/pp.18.01334

Osakabe Y, Yamaguchi-Shinozaki K, Shinozaki K, Tran LS (2014) ABA control of plant macroelement membrane transport systems in response to water deficit and high salinity. New Phytol 202:35-49. doi: 10.1111/nph.12613. 
Pacini E, Dolferus (2019) Pollen Developmental Arrest: Maintaining Pollen Fertility in a World With a Changing Climate. Front. Plant Sci 10:1-15. DOI=10.3389/fpls.2019.00679

Peleg Z, Apse MP, Blumwald E (2011) Engineering salinity and water-stress tolerance in crop plants: getting closer to the field. Adv Bot Res 57:405-443.

Reis RR, da Cunha BADB, Martins PK, Martins MTB, Alekcevetch JC, Chalfun-Júnior A, Andrade AC, Ribeiro AP, Qin F, Mizoi J, Yamaguchi-Shinozaki K (2014) Induced over-expression of AtDREB2A CA improves drought tolerance in sugarcane. Plant Sci 221:59-68.

Ren M, Wang Z, Xue M, Wang X, Zhang F, Zhang Y, Zhang W, Wang M (2019) Constitutive expression of an A-5 subgroup member in the DREB transcription factor subfamily from Ammopiptanthus mongolicus enhanced abiotic stress tolerance and anthocyanin accumulation in transgenic Arabidopsis. PLoS One 14(10):e0224296. doi: 10.1371/journal.pone.0224296. Erratum in: PLoS One 14(12):e0227290.

Rotsch AH, Kopka J, Feussner I, Ischebeck T (2017) Central metabolite and sterol profiling divides tobacco male gametophyte development and pollen tube growth into eight metabolic phases. Plant $\mathrm{J} 92$ : 129-146. https://doi.org/10.1111/tpj.13633

Santos MP, Zandonadi DB, de Sá AFL, Costa EP, de Oliveira CJL, Perez LEP, Façanha AR, Bressan-Smith R (2020) Abscisic acid-nitric oxide and auxin interaction modulates salt stress response in tomato roots. Theor Exp Plant Physiol 32:301-313.

Schmidt GW, Delaney SK (2010) Stable internal reference genes for normalization of real-time RT-PCR in tobacco (Nicotiana tabacum) during development and abiotic stress. Mol Genet Genomics 283:233-241.

Sharma P, Singh R, Sehrawat N (2020) A critical review on: Significance of floral homeotic APETALA2 gene in plant system. J Appl Pharm Sci 10:124-130. http://DOI:10.7324/JAPS.2020.101017.

Shinwari ZK, Jan SA, Nakashima K, Yamaguchi-Shinozaki K (2020) Genetic engineering approaches to understanding drought tolerance in plants. Plant Biotechnol 14:151-162.

Srivastava R, Kumar R (2019). The expanding roles of APETALA2/Ethylene Responsive Factors and their potential applications in crop improvement. Brief Funct Genomics 18:240-254.

Strizhov N, Abrahám E, Okrész L, Blickling S, Zilberstein A, Schell J, Koncz C, Szabados L (1997) Differential expression of two P5CS genes controlling proline accumulation during salt-stress requires ABA and is regulated by ABA1, ABI1 and AXR2 in Arabidopsis. Plant J 12:557-569. doi: 10.1046/j.1365313x.1997.00557.x.

Sun B, Looi LS, Guo S, He Z, Gan ES, Huang J, Xu Y, Wee WY, Ito T (2014) Timing mechanism dependent on cell division is invoked by Polycomb eviction in plant stem cells. Sci 343:1248559. 
Székely G, Abrahám E, Cséplo A, Rigó G, Zsigmond L, Csiszár J, Ayaydin F, Strizhov N, Jásik J, Schmelzer E, Koncz C, Szabados L (2008) Duplicated P5CS genes of Arabidopsis play distinct roles in stress regulation and developmental control of proline biosynthesis. Plant J 53:11-28. doi: 10.1111/j.1365313X.2007.03318.x.

Takahashi F, Kuromori T, Urano K, Yamaguchi-Shinozaki K, Shinozaki K (2020) Drought stress responses and resistance in plants: From cellular responses to long-distance intercellular communication. Front Plant Sci 11:1-14. https://doi.org/10.3389/fpls.2020.556972.

Taleisnik E, Peyrano G, Córdoba A, Arias C (1999) Water retention capacity in root segments differing in the degree of exodermis development. Ann Bot 83:19-27.

Upadhyay RK, Gupta A, Soni D, Garg R, Pathre UV, Nath P, Sane AP (2017) Ectopic expression of a tomato DREB gene affects several ABA processes and influences plant growth and root architecture in an agedependent manner. J Plant Physiol 214:97-107. doi: 10.1016/j.jplph.2017.04.004.

Vieira PM, Santos MP, Andrade CM, Souza-Neto OA, Ulhoa CJ, Aragão FJL (2017) Overexpression of an aquaglyceroporin gene from Trichoderma harzianum improves water-use efficiency and drought tolerance in Nicotiana tabacum. Plant Physiol Biochem 121:38-47.

http://dx.doi.org/10.1016/j.plaphy.2017.10.012

Wang Z, Ji H, Yuan B, Wang S, Su C, Yao B, Zhao H, Li X (2015) ABA signalling is fine-tuned by antagonistic HAB1 variants. Nat Commun 6:1-15. doi: 10.1038/ncomms9138.

Xie M, Wu D, Duan G, Wang L, He R, Li X, Tang D, Zhao X, Liu X (2014) AtWNK9 is regulated by ABA and dehydration and is involved in drought tolerance in Arabidopsis. Plant Physiol Biochem 77:73-83 https://doi.org/10.1016/j.plaphy.2014.01.022.

Yin X, Cui Y, Wang M, Xia X (2017) Overexpression of a novel MYB-related transcription factor, OsMYBR1, confers improved drought tolerance and decreased $A B A$ sensitivity in rice. Biochem Biophys Res Commun 490:1355-1361. doi: 10.1016/j.bbrc.2017.07.029.

\section{Figures}


a

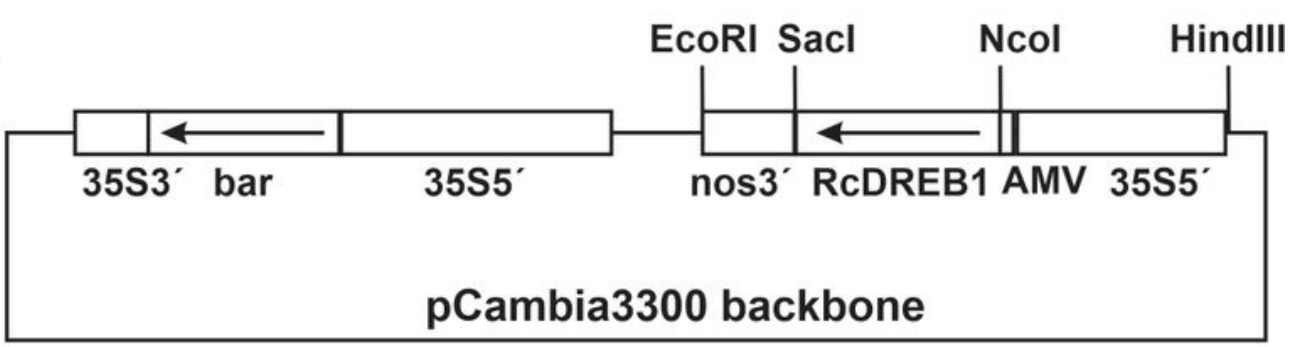

b

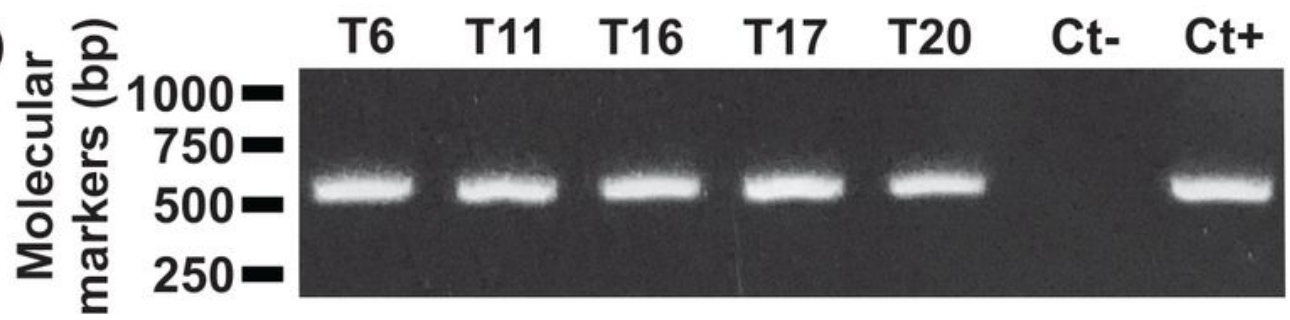

Ct- T6 T11 T16 T17 T20

C

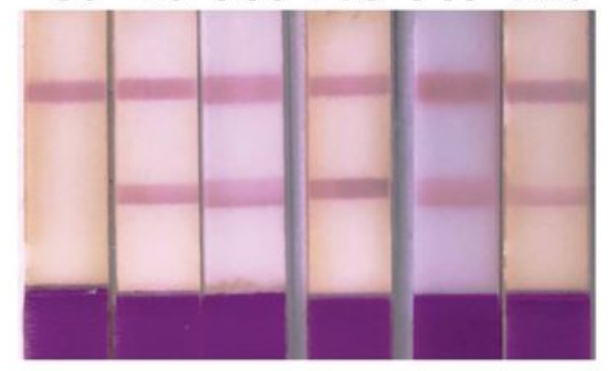

Control

PAT

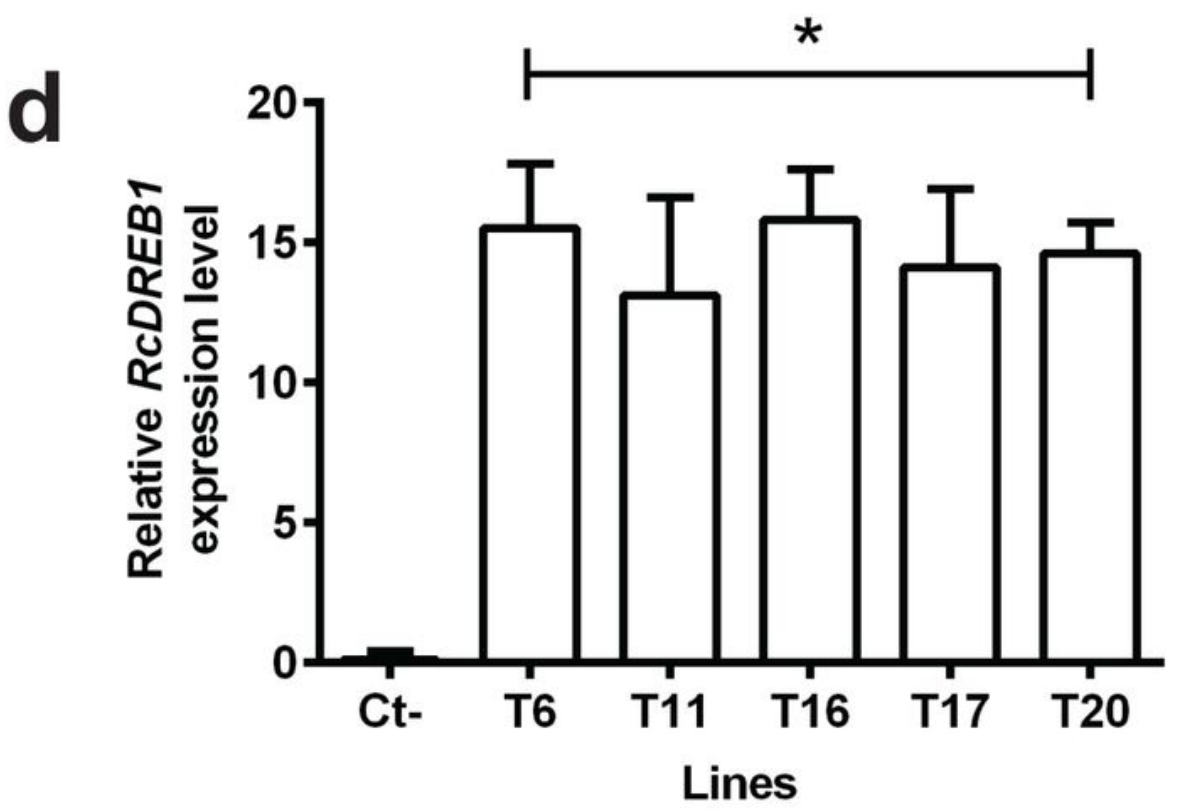

Figure 1

a) Diagram of the vector pC-RcDREB1 used to overexpress the RcDREB1 gene from R. communis in transgenic tobacco plants. The RCDREB1 gene was cloned under the control of the 35S RNA promoter from the Cauliflower mosaic virus promoter (35S5') and the Alfalfa mosaic virus enhancer (AMV). The RcDREB1 cassette was cloned into the pCambia3300 vector, which contains the bar gene, which confers tolerance to glufosinate-ammonium, used for selection of transformed plants. b) PCR analysis for 
detection of the RcDREB1 gene in transformed lines. c) Immuno-chromatographic analyses for the expression of the bar gene (presence of PAT protein). d) Quantitative real-time PCR to quantify the expression of the RcDREB1 gene in leaves of transgenic and non-transgenic (control) tobacco lines. Data represent means of three biological and three technical replications, related to control. Ct-: non-transgenic plants; $\mathrm{Ct}+$ vector. Bars represent $\pm \mathrm{SE}$. $* \mathrm{P}<0.05$.
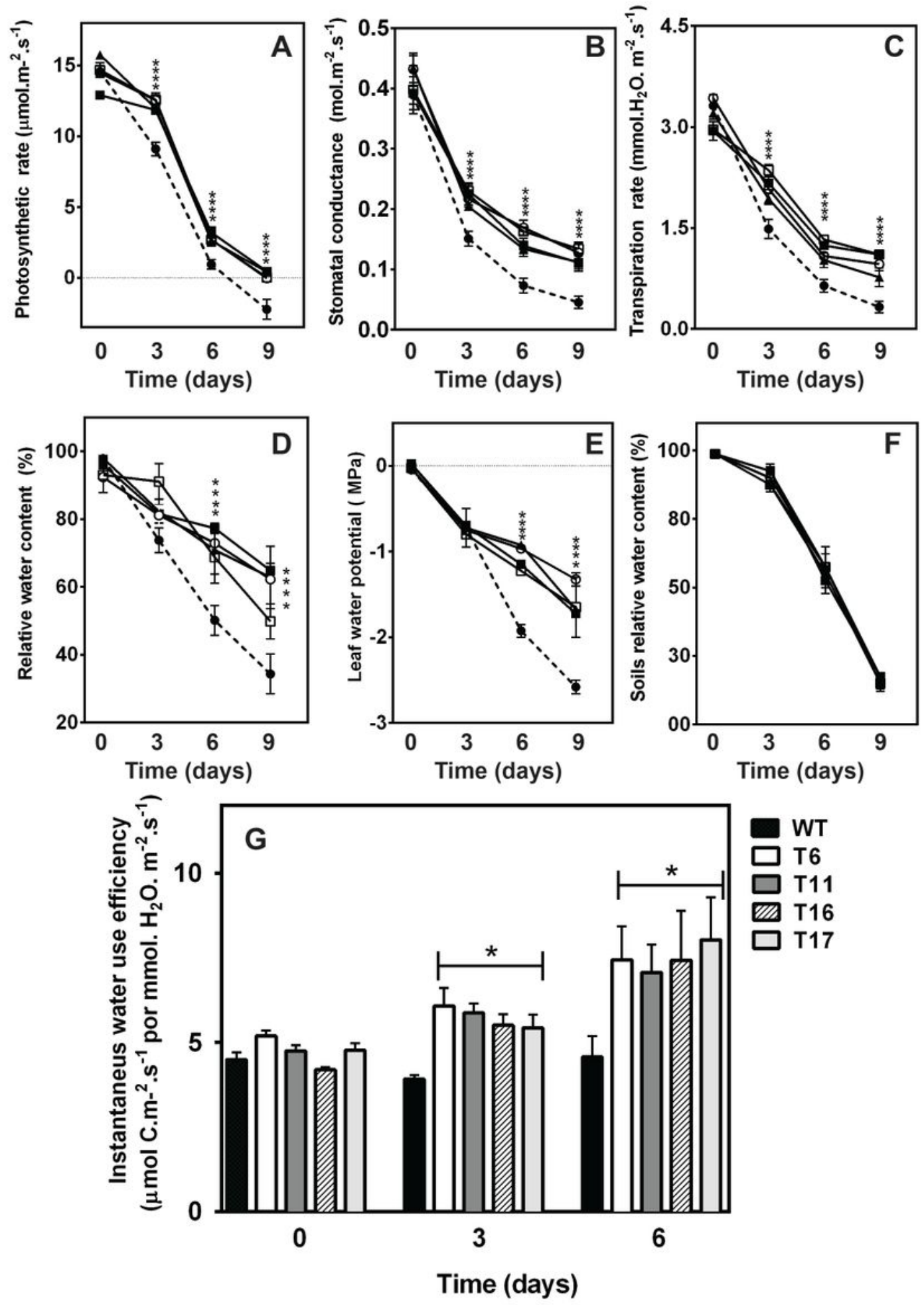

Figure 2 


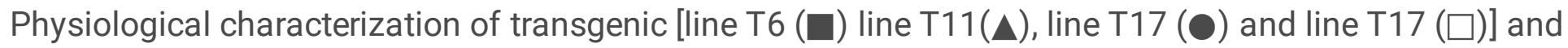
non-transgenic lines [WT ( $(\mathbf{O})$ in response to water shortage for a period of nine days. F shows the relative water content of the soil in which plants were cultivated and maintained under water shortage for nine days. Bars represent $\pm S E$. * $P<0.05, n=16$.

control line $\mathrm{T6}$

line T16 line T17
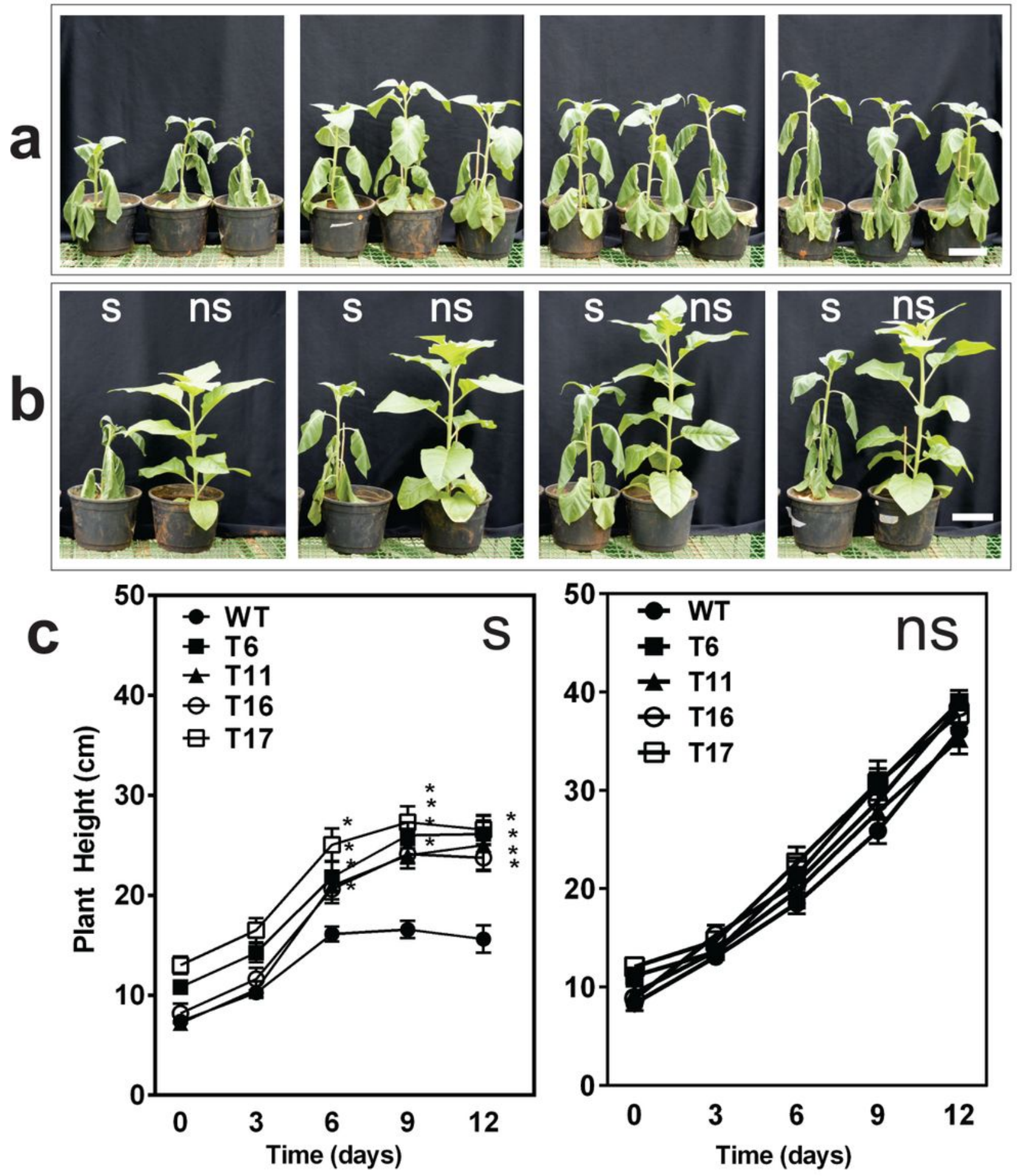

Figure 3 
Transgenic plants (lines T6, T11, T16 and T17) expressing the RcDREB1 gene exposed to water-deficit stress. a) Three transgenic and non-transgenic (WT) 79-day-old plants nine days after irrigation withdrawal. b) Comparison of the 79-day-old transgenic and non-transgenic plants exposed (s) and nonexposed (ns) to water stress for nine days. c) Plant development for the period of 12 days exposed (s) and not exposed to stress. Bars represent \pm SE. ${ }^{*} \mathrm{P}<0.05, \mathrm{n}=16$.
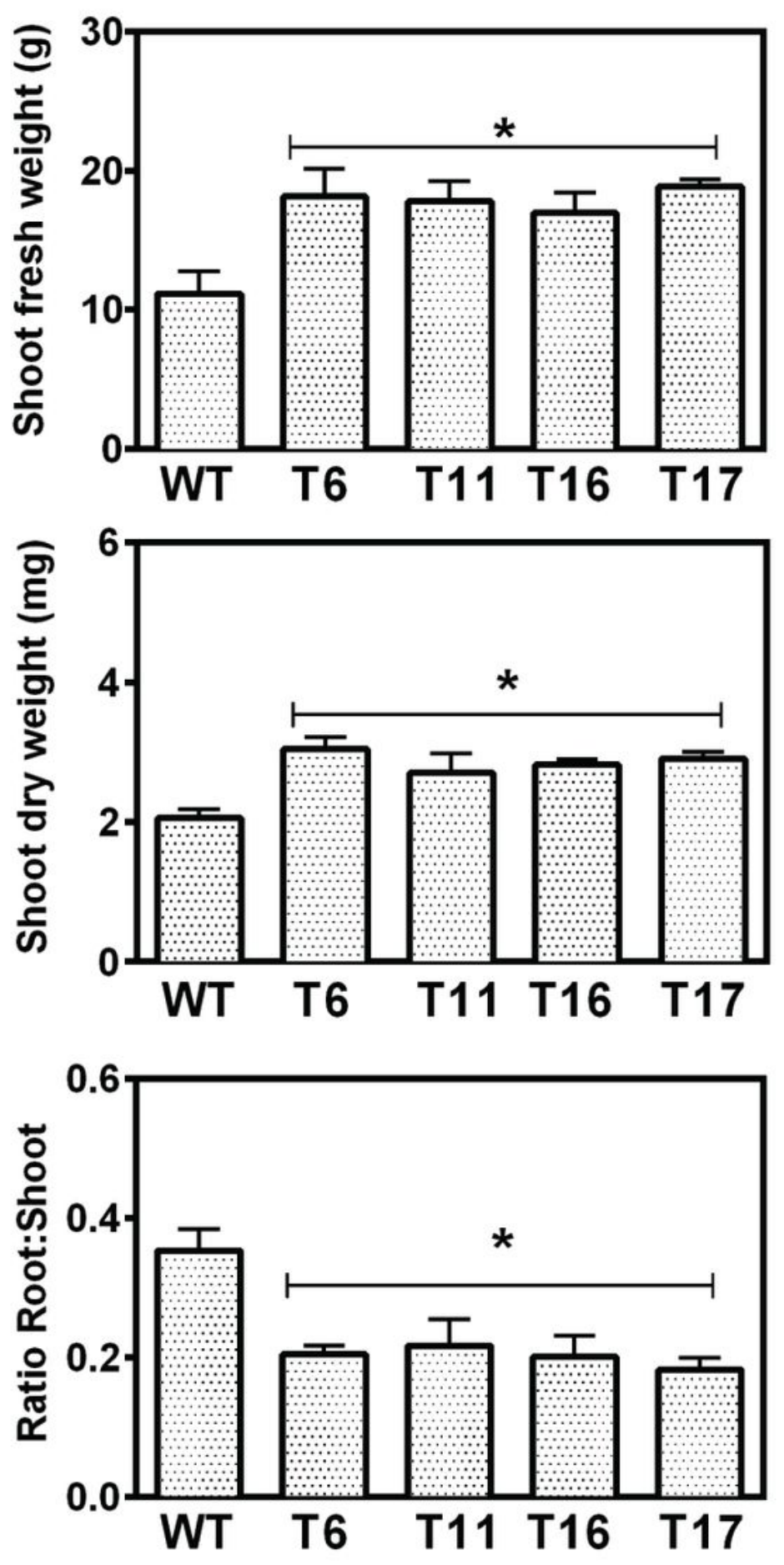

Figure 4 
Biometric characterization performed with transgenic ( $\mathrm{T} 6, \mathrm{~T} 11, \mathrm{~T} 16$ and $\mathrm{T} 17 ; \mathrm{T} 2$ generation) and nontransgenic lines (WT) after nine days under water stress. Bars represent $\pm S E$. ${ }^{*} P<0.05, n=16$.

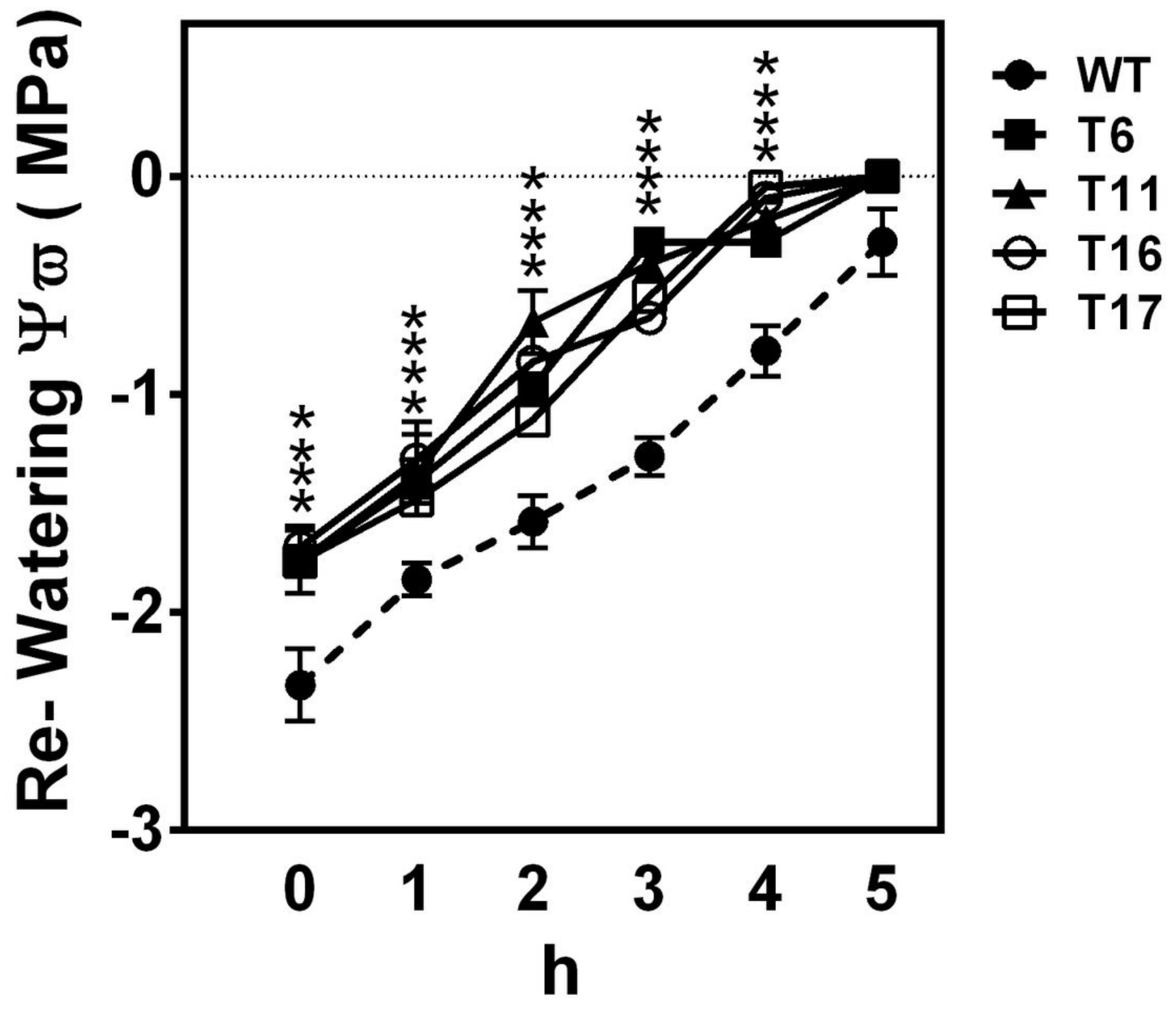

Figure 5

Transgenic (T6, T11, T16 and T17; T2 generation) and non-transgenic (WT) lines were maintained under water shortage for nine days and then re-watered. The leaf water potential $\left(\Psi_{\mathrm{W}}\right)$ was measured for five hours (B). Bars represent \pm SE. * $P<0.05, n=16$. 

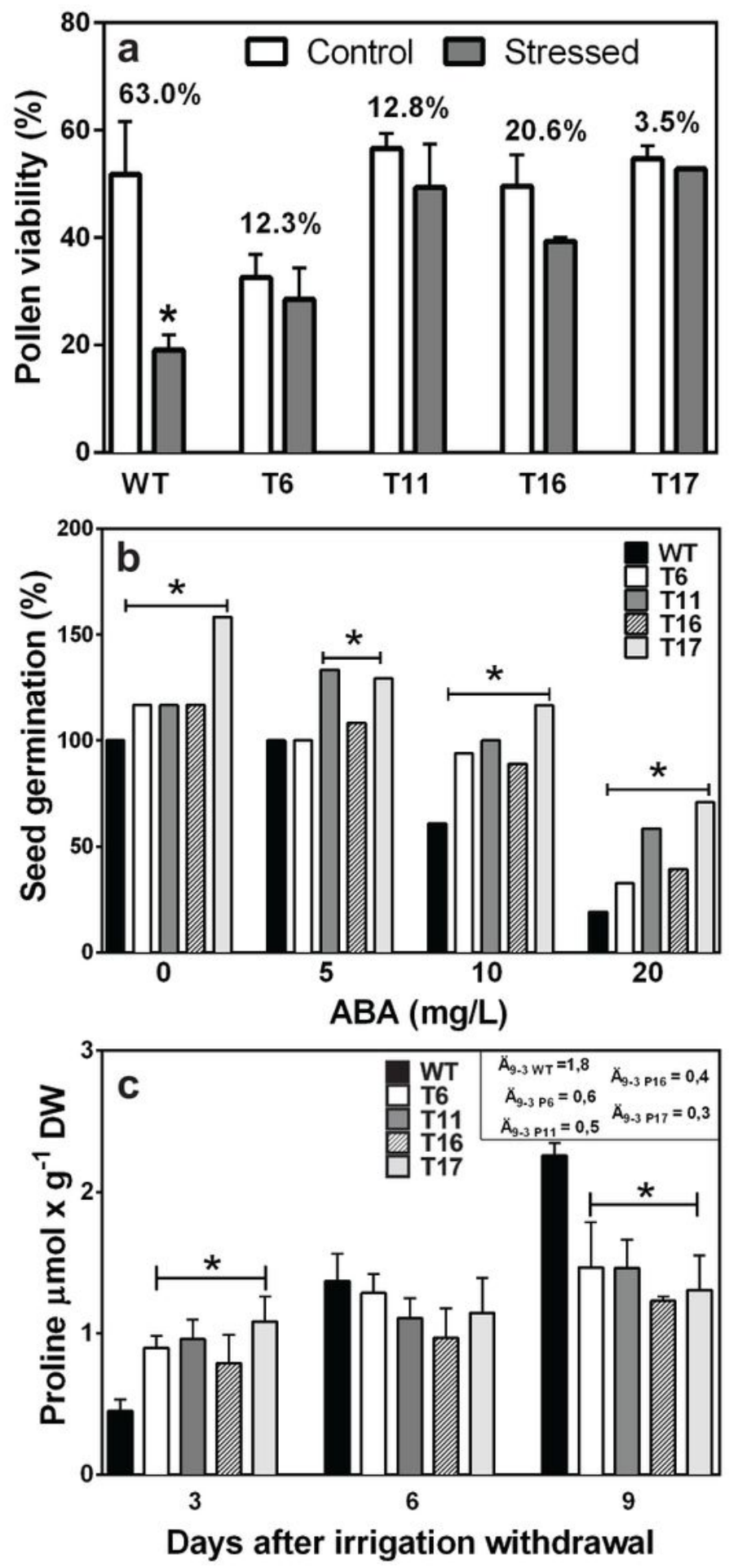

Figure 6

a) Viability of pollens from transgenic ( $T 6, T 11, T 16$ and $T 17)$ and non-transgenic (WT) plants exposed to heat $\left(38^{\circ} \mathrm{C}\right)$ and desiccation stresses. The reduction in viability (\%) is annotated. b) Effect of abscisic acid (ABA) on seed germination. c) Quantification of proline content in leaves of transgenic and nontransgenic plants 3, 6 and 9 days after irrigation removal. Bars represent $\pm S E$. ${ }^{*} P<0.05, n=16$. 